\title{
Organizational Conditioning of Job Satisfaction. A Model of Job Satisfaction
}

\author{
Marcin Wnuk ${ }^{1}$
}

ABSTRACT

KEY WORDS:

Job satisfaction is an important predictor of job switching. Knowledge of the predictors of job satisfaction offers business owners and management staff the ability to shape the work environment so that the most valuable, loyal, and experienced employees can be retained in the company.

The objective of this project is to test a model of job satisfaction based on person-organization fit (P-O fit), perceived organizational support (POS), and perceived supervisor support (PSS). The study examines whether PSS directly relates to employee job satisfaction or whether P-O fit or POS mediate in this relationship. Additionally, it is examined whether POS is a moderating variable between P-O fit and job satisfaction.

The study was conducted using a sample 484 employees of a company in the IT sector.

It turns out that POS, and P-O fit to the organization are variables that act as partial mediator between PSS and job satisfaction. The relationship between PSS and POS is both direct and indirect. P-O fit is a partial mediator of this relationship, while POS is both a partial mediator and a moderator between P-O fit and job satisfaction. Among employees who POS to be high, consistency between an employee's and the organization's values is indirectly connected with job satisfaction, whereas among employees who POS to be low, this relationship is both direct and indirect. In their operations, employers should focus on shaping managers' attitudes towards their subordinates in an appropriate direction, as managers significantly influence employees' perceived organizational support and job satisfaction.

job satisfaction, person-organization fit, perceived organizational support, perceived supervisor support

JEL Classification: J28

${ }^{1}$ Adam Mickiewicz University, Department of Work and Organizational Psychology, Poland

\section{Introduction}

Job satisfaction is among the most commonly discussed phenomena in the psychology of business and human resource management, attesting to the importance it

Correspondence concerning this article should be addressed to: Marcin Wnuk, Adam Mickiewicz University, Department of Work and Organizational Psychology, Institute of Psychology, Szamarzewskiego street 89/AB, Poznań, Poland. E-mail: Marcin.Wnuk@komputronik.pl carries. The relevant literature treats job satisfaction as the key factor in commitment to one's job (Brown \& Peterson, 1993) or the intend to quit and change it (Liu, Liu, \& Hu, 2010; Park \& Kim, 2009). Sources of job satisfaction among the employed are also a major focus of enquiry, so that they can be used to amplify perceived job satisfaction and thus increase employees' effectiveness and commitment and decrease motivation to quit jobs. Research conducted to date has found that perceived organizational support (Galletta, 
Portoghese, Penna, Battistelli, \& Saiani, 2011; Harris, Harris, \& Harvey, 2007), supervisor support (Podsakoff, MacKenzie, \& Bommer, 1996; Schaubroeck \& Fink, 1998), and person-organization fit (Iplik, Kilic, \& Yalcin, 2011; Narayanan \& Sekar, 2009) are important elements of job satisfaction.

The aim of this article is to verify the model of job satisfaction on the basis of such organizational variables as supervisor and organizational support, personorganization fit, and the mutual relations among them. Knowledge of the organizational conditioning of job satisfaction carries significant practical value, as it offers employers a means of positively shaping job satisfaction and retaining the most valuable employees.

\section{Literature review}

The consistency between some aspects of employees' private lives and their operations at work exerts influence over the decisions and professional choices they make. Employees searching for a job select offers based on perceived and alleged consistency between their values and the values held by the company they apply to. This relationship has a two-sided character, as employers also strive for axiological consistency between employees and the organization; thus, they use tools to verify consistency between the organization's values and those of job candidates in their recruitment practices (Werbel \& Gilliland, 1999).

Based on premises provided in the literature regarding attachment in the context of models of job switching, the construct of so-called job embeddedness is increasingly commonly examined (Mitchell, Holtom, Lee, Sablynski, \& Erez, 2001). It is composed of three main elements that shape attachments between employees and their work environments understood broadly and is connected with the network of ties that anchor an employee to one's job. The first is concerned with relationships with co-workers and various types of actions and activities at work. The second is focused on similarities and the fit between work and other aspects of operations in one's living space. The third is connected with the ease of breaking the links enumerated above, especially if a change of job entails a change of residence. The relevant literature refers to the above elements as links, fit, and sacrifice.

In line with the concept of job embeddedness, the personal values of employees, their objectives related to their professional careers, and their plans for the future must be suited to the broad corporate culture of an organization and their own requirements for a job. An employee considers how suited one is to the community within which one is placed and the surrounding environment. In line with previous research, fit in this respect reduces intention to leave and change one's job and simultaneously exerts a positive influence on job satisfaction (Tanovaa \& Holtom, 2008).

Based on the social exchange theory proposed by Blau in 1964, it may be stated that an employee perceives organizational support (POS) through the prism of one's supervisor, who is a representative of the company and personifies it. It is the direct supervisor, as the closest representative of an organization, who communicates to the subordinates the company's intentions regarding the employees. Through the supervisor, subordinates gain insight into the organizational culture, co-workers, the authority of management, the usefulness of certain skills, organizational values, and responsibility. All these elements form the construct of job fit, which is different from perceived organizational support, as the former relates to comfort experienced in an organization, whereas the latter concerns an employee's conviction that an organization appreciates one's contribution to its development and welfare (Eisenberger, Huntington, Hutchison, \& Sowa, 1986). Organizational support perceived by an employee is the outcome of an employee's subjective perception of what the organization offers through one's supervisor, whereas job fit becomes stronger if the organization offers a working environment that is consistent with employees' values, professional objectives, skills, competences, and knowledge.

Perceived supervisor support (PSS) as well as fit with the company influence perceived organizational support. This is reflected in research (Dawley, Houghton, \& Bucklew, 2010) in which job fit mediate between a partial intermediary between supervisor support and perceived organizational support. This means that the relationship between a supervisor's support and organizational support may have both a direct and indirect character.

Multiple studies confirm the positive correlation between POS and PSS (Hutchison, 1997; Kottke \& Sharafinski, 1988; Rhoades, Eisenberger, \& Armeli, 2001; Yoon, Han, \& Seo, 1996; Yoon \& Lim, 1999), clearly 

ment (O'Reilly, Chatman, \& Caldwell, 1991), confirms the existence of a positive correlation between consistency of an organization's and an employee's values and the employee's job satisfaction and commitment to the organization. In a study of four Canadian organizations, Piasentin and Chapman (2007) showed that subjective perceptions of person-organization fit mediate between a sense of similarity and complementarity of employees to the organization and job satisfaction. In research conducted on employees of six organizations in the United States, consistency between employee and company values as well as between employees' ideal vision of the work environment and their evaluation of the current work environment were positively correlated with job satisfaction (Westerman \& Cyr, 2004). This dependency was confirmed by other studies conducted on employees in the United States (Lauver \& Kristof-Brown, 2001). Analogous results were obtained among employees in Spain (Vilela, González, \& Ferrín, 2008), teachers in India (Narayanan \& Sekar, 2009), and managers of hotels in Turkey (Iplik et al., 2011).

In line with research conducted on employees of five Turkish banks, perceived supervisor support turned out to be a moderator of the correlation between person-organization fit and job satisfaction (Maden \& Kabasakal, 2014).

Erdogan, Kraimer, and Liden (2004) corroborated the mediating role of organizational support between person-organization fit and values and job satisfaction of teachers in Turkey. A moderating function for organizational support was not confirmed for other types of the person-organization fit.

Hypothesis 4. Person-organization fit is positively correlated with job satisfaction. Organizational support plays a moderating role in this correlation.

\section{Methodology}

\section{Description of the research sample}

The study was conducted on 485 individuals working in a single large organization. The participants included 97 women (i.e., $20 \%$ ) and 388 men (i.e., $80 \%$ ). Among responses to the survey, $21.7 \%$ were from of employees who had been employed between 1 and 12 months (short seniority), $30.6 \%$ were from employees who had been employed between 12 and 48 months (medium seniority), and $47.7 \%$ were from employees who had seniority of over 48 months (long seniority). Mean seniority was 3.06 years $(\mathrm{SD}=3.31)$, and mean age was 31.5 years $(\mathrm{SD}=7.75)$. Seventeen employees surveyed (i.e., 3.51\%) had vocational education, 250 (51.54\%) had secondary education, and 218 (44.95\%) had higher education. Members of the management board, department directors, division and branch directors, and division and team managers composed a group of 97 employees surveyed (i.e., 20\%). The number of other employees who did not hold managerial positions was 388 (i.e., 80\%). The survey was anonymous. All participants agreed to take part in the study.

\section{Research tools}

The following research tools were adopted:

Identification with company values was tested using the Person-Organization Fit Scale, consisting of three questions (Cable \& DeRue, 2002). Examples of questions in the scale are: "My organization's values and culture provide a good fit with the things that I value in life.", "The things that I value in life are very similar to the things that my organization values". Responses were provided on a 5 -point scale ranging from "I definitely disagree" to "I definitely agree" and then summed up. The reliability of this tool is $\alpha=0.90$.

The examination of organizational support was carried out with a shorter version of the Perceived Organizational Support Scale, comprising 8 questions. In line with the recommendation of Rhoades and Eisenberger (2002), owing to the one-factor character of this tool and a high level of reliability, the use of a shorter version appears to be legitimate. The questions used in this study were selected based on a factor analysis, with balance maintained between negative and positive statements (Eisenberger et al., 1986). Some examples of questions used are the following: "The organization values my contribution to its well-being". "The organization ignore any complaint from me". "The organization really cares about my well-being". "The organization shows very little concern for me". "The organization takes pride in my accomplishments at work". Responses were provided on a 5-point scale ranging from "I definitely disagree" to "I definitely agree" and then summed up. The reliability of this tool is $\alpha=0.90$. 
Table 1. Descriptive statistics of the variables used in the study ( $n=485$ )

\begin{tabular}{lccccccc}
\hline & N & Min. & Max & M & SD & Skewness & Kurtosis \\
\hline Job satisfaction & 484 & 3 & 21 & 14.07 & 4.28 & -0.42 & -0.16 \\
Person-organization fit & 484 & 0 & 12 & 6.18 & 2.77 & -0.31 & -0.32 \\
Perceived organizational support & 484 & 0 & 32 & 14.11 & 7.00 & 0.06 & -0.63 \\
Perceived supervisor support & 484 & 0 & 12 & 7.96 & 3.31 & 0.75 & -0.22 \\
\hline
\end{tabular}

Table 2. The coefficients of correlation between variables used in the study ( $n=485$ )

\begin{tabular}{|c|c|c|c|c|}
\hline & 1 & 2 & 3 & 4 \\
\hline \multicolumn{5}{|l|}{ 1. Job satisfaction } \\
\hline 2. Person-company fit & $0.56^{* *}$ & & & \\
\hline 3. Perceived organizational support & $0.67 * *$ & $0.61^{* *}$ & & \\
\hline 4. Perceived supervisor support & $0.56^{* *}$ & $0.38^{* *}$ & $0.59 * *$ & \\
\hline 5. Job seniority & $-0.18^{* *}$ & $-0.23^{* *}$ & $-0.31^{* *}$ & $-0.20^{* *}$ \\
\hline
\end{tabular}

Supervisor support was measured using the Perceived Supervisor Support Scale, comprising three questions adapted by way of changing the word "organization" to "supervisor" in the Survey of Perceived Organizational Support, authored by Eisenberger et al. (1986). The respondents answered the following questions: " $M y$ supervisor cares about my general satisfaction at work". "My supervisor really cares about my well-being". "I enjoy working with my supervisor". Responses were provided on a 5-point scale ranging from "I definitely disagree" to "I definitely agree" and then summed up. The reliability of this measure was estimated to be $\alpha=0.93$

Job satisfaction was tested using the Michigan Organizational Assessment Questionnaire (Cammann, Fichman, Jenkins, \& Klesh, 1979). This tool consists of the following three questions: "All in all I am satisfied with my job". "In general, I don't like my job". "In general, I like working here". Responses were provided on a 7-point scale ranging from "I definitely disagree" to "I definitely agree" and then summed up. The reliability of this tool was $\alpha=0.79$.

\section{Results}

Estimations were performed using Amos software, version 23. Descriptive statistics are provided in table 1. Because variables in the model were approximately normally distributed (as both kurtosis and skewness fell in the range $(-1: 1)$ ), the maximum likelihood method was adopted.

To verify goodness of fit of the model, the most commonly adopted indicators, such as NFI, GFI, CFI, AGFI, and RMSA, were used. Based on the coefficients of correlation obtained, job seniority in the current company was included in the model, as this variable was correlated with all the other variables in the model (table 2). Following introduction of this variable, job seniority was found to be directly related to perceived organizational support, supervisor support, and person-organization fit and only partially related to job satisfaction, as reflected in the final model (schema 1).

Based on the relevant literature, for a model to be considered fitted, NFI should exceed 0.90, GFI should exceed 0.90, and CFI should exceed 0.93 (Byrne, 


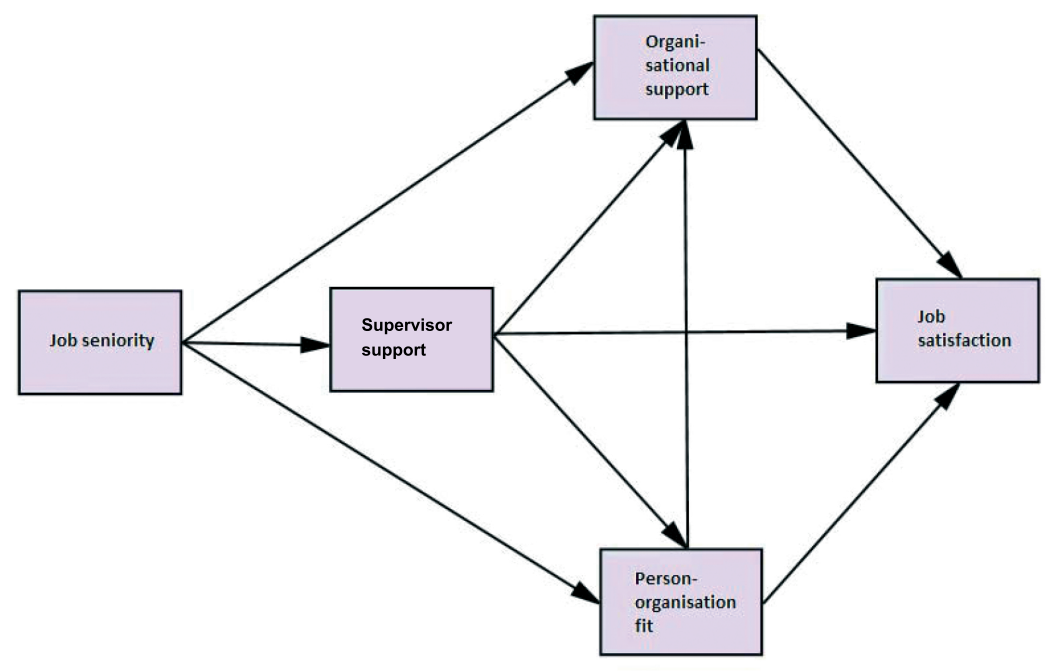

Schema 1. Model of job satisfaction based on person-organization fit and perceived organizational and supervisor support.

1994). On the other hand, RMSA should fall below 0.08 (Browne \& Cudeck, 1993) and ideally below 0.05 (Stieger, 1990). In line with Kline's (1998) and Ullman's (2001) suggestion, relative chi-square should be below 2 or 3 .

The values of selected indicators obtained $(\mathrm{CMIN}=1.64 ; \mathrm{p}=0.202 ; \mathrm{RMSA}=0.036, \mathrm{NFI}=0.98$, $\mathrm{GFI}=0.99$, AGFI=0.98; CFI=0.98) confirm a very good model fit. The total, direct, and indirect results in the case of mediation are provided in tables 3, 4, and 5.

Support from a supervisor was positively and directly correlated with person-organization fit and both directly and indirectly correlated with perceived organizational support, while the variable that acted as a partial mediator in this relationship was personorganization fit. Person-organization fit was positively correlated, both directly and indirectly, with job satisfaction. The mediator of this correlation was organizational support.

Verification of the moderating role of perceived organizational support in the relationship between person-organization fit and job satisfaction was per- formed using regression analysis after prior standardization of variables and estimation of the interaction term (Bedyńska \& Książek, 2013).

Variance analysis demonstrated that the regression model with the interaction term is significant $(\mathrm{F}=149.55 ; p<0.001)$; that is, it is well-fitted to the data. The standardized beta coefficient for the interaction effect was statistically significant and amounted to -0.07 . The significance level of the $\mathrm{R}$ square change after taking into consideration the interaction effect was statistically significant $(\mathrm{F}=79.77 ; p<0.001)$ and amounted to 0.48 . This means that perceived organizational support moderates the correlation between person-organization fit and job satisfaction.

To provide additional verification of the moderating role of organizational support, Preacher and Hayes's (2008) method was applied, with respondents divided into those with high organizational support and those with low organization support. Among employees with low perceived organizational support, the influence of person-organization fit on job satisfaction $(c=0.618$, $\mathrm{t}=7.55, p=0.0000)$ was reduced $\left(c^{\prime}=0.447, \mathrm{t}=5.19\right.$, 
Table 3. Standardized total effect between variables used in the study ( $n=485$ )

\begin{tabular}{lcccc}
\hline & Job seniority & PSS & P-O Fit & POS \\
\hline Supervisor support & -0.20 & 0.00 & 0.00 & 0.00 \\
Person-organization fit & -0.23 & 0.35 & 0.00 & 0.00 \\
Organizational support & -0.31 & 0.55 & 0.45 & 0.00 \\
Job satisfaction & -0.22 & 0.54 & 0.39 & 0.38 \\
\hline
\end{tabular}

Note:

POS - abbreviation for Perceived Organizational Support

PSS - abbreviation for Perceived Supervisor Support

P-O Fit - abbreviation for Person-Organization Fit

Table 4. Standardized direct effect between variables used in the study ( $n=485$ )

\begin{tabular}{lcccc}
\hline & Job seniority & PSS & P-O Fit & POS \\
\hline Supervisor support & -0.20 & 0.00 & 0.00 & 0.00 \\
Person-organization fit & -0.16 & 0.34 & 0.00 & 0.00 \\
Organizational support & -0.12 & 0.40 & 0.45 & 0.00 \\
Job satisfaction & 0.00 & 0.25 & 0.22 & 0.38 \\
\hline
\end{tabular}

Table 5. Standardized indirect effect between variables used in the study ( $n=485)$

\begin{tabular}{lcccc}
\hline & Job seniority & PSS & P-O Fit & POS \\
\hline Supervisor support & 0.00 & 0.00 & 0.00 & 0.00 \\
Person-organization fit & -0.07 & 0.00 & 0.00 & 0.00 \\
Organizational support & -0.19 & 0.16 & 0.00 & 0.00 \\
Job satisfaction & -0.22 & 0.29 & 0.17 & 0.00 \\
\hline
\end{tabular}

$p=0.0000)$, due to the impact of organizational support $(Z=3.95, p=0.0001)$. This means that for this group, organizational support acts as a partial mediator between person-organization fit and job satisfaction. Among employees with high perceived organizational support, the influence of person-organization fit on job satisfaction $(c=0.458, \mathrm{t}=4.78, p=0.0000)$ was reduced to a statistically insignificant level $\left(c^{\prime}=0.166\right.$, $\mathrm{t}=1.61, p=0.1085)$, due to organizational support $(\mathrm{Z}$ $=4.82, p=0.0000)$. This shows that for this group, or- ganizational support totally mediate between personorganization fit and job satisfaction.

It turned out that among employees with a low level of organizational support, the fit to an organization's values is both directly and indirectly related to job satisfaction, and organizational support plays a partial mediating role in this relation. By contrast, among employees with a high level of organizational support, the fit to an organization's values is only partially correlated with job satisfaction. 
Based on the results described above, it may be stated that organizational support is not only a partial mediator but also a moderator of the correlation between fit with an organization's values and job satisfaction.

Supervisor support is both directly and indirectly correlated with job satisfaction. To verify whether only a single variable - organizational support mediate in this correlation or whether person-organization also does so, Preacher and Hayes's method was adopted (2008). Following incorporation of all the variables into the model, it turned out that the influence of supervisor support on job satisfaction $(c=0.728, \mathrm{t}=14.95, p=0.0000)$ was reduced $\left(c^{\prime}=0.327, \mathrm{t}=6.42, p=0.0000\right)$, due to organizational support $(Z=7.24, p=0.0000)$ and person-organization fit $(Z=4.72, p=0.0000)$, which means that both these variables act as partial mediator in this correlation.

Variables such as age and education were not analyzed, as nearly all employees were between 25 and 45 years of age and had either secondary or higher education.

\section{Discussion of the results}

The hypothesis that person-organization fit acts as a partial mediator between supervisor support and perceived organizational support was fully confirmed. Supervisor support was directly correlated with organizational support and person-organization fit and indirectly related to organizational support through person-organization fit as a positive correlate of organizational support. The direction of the correlation between both variables also turned out to be consistent with the results of other research, indicating that perceived supervisor support is a source of perceived organizational support (Hutchison, 1997; Kottke \& Sharafinski, 1988; Rhoades et al., 2001; Yoon et al., 1996; Yoon \& Lim, 1999). As found in a study conducted by Dawley et al. (2010), the correlation between supervisor support and organizational support was both direct and indirect, the only difference being that the mediator of this correlation was person-organization fit.

This means that the correlation between supervisor support and organizational support is based on two separate mechanisms. One concerns the direct influence of perceived supervisor support on support from a company, as perceived by the employee. In the second case, we are dealing with a more complex process in which the employee notices the supervisor support and equates it with consistency of the employee's own values with those of the organization, compelling the employee to believe that the organization offers greater support.

The results obtained may be interpreted on the basis of the theory of social exchange, in which one party is an employee and the other an organization, with transactions between these parties made through the agency of the direct supervisor of the employee (Blau, 1964). Based on the rule of reciprocity, employees see such a relationship from the perspective of profits and losses, wondering what they gain from the organization and how they are treated by it to be able to reciprocate (Levinson, 1965). The intentions of the organization are seen by employees through the prism of the supervisor, who personifies the organization. If an activity undertaken by the supervisor as the representative of the organization is seen by the employee as favorable, it contributes to an increase of organizational support, as perceived by the employee. The power of this correlation depends on the degree to which the employee equates the supervisor with the organization. The more autonomous is the activity of the supervisor in the eyes of the employee, the lower this degree is (Eisenberger et al., 2002).

Based on the results obtained, it may be stated that organizational support is also perceived by an employee through the prism of person-organization fit, specifically, through consistency between the employee's values and those of the company. In this case as well, the supervisor appears to play the key role, as perceived supervisor support increases the employee's conviction that his or her values are consistent with the company's values, which makes the employee feel greater support from the organization. In this context, the supervisor is treated as a carrier of company values, and the perceived consistency between the organization's and employee's values exerts a positive influence on organizational support, as seen by the employee.

The hypothesis of a positive correlation between perceived organizational support and job satisfaction is fully supported, with positive correlations found between organizational support and job satisfac- 

the impact of person-organization fit is greater than the indirect effect (tables 4 and 5).

The results of this study also confirm the mediating role of perceived organizational support between the person-organization fit and job satisfaction. It turns out that for people who declare greater organizational support, perceived consistency between their values and those of the organization is not directly correlated with job satisfaction. For respondents whose level of organizational support is low, person-organization fit is both directly and indirectly correlated with job satisfaction. In the present context, organizational support turns out to be both a mediator and a moderator between person-organization fit and job satisfaction. In the relevant literature, a situation in which a single variable plays the role of both mediator and moderator is fairly rare (Baron \& Kenny, 1986; Preacher, Rucker, \& Hayes, 2007).

In accordance with the results of this study, job seniority at one's current job exerts an indirect influence on job satisfaction through person-organization fit and perceived supervisor and company support. This means that along with job seniority, perceived support from an organization and the supervisor as well as consistency between the employee's and the organization's values decrease, which reduces job satisfaction. Due to a lack of research on this issue, the results may be interpreted mainly in terms of mechanisms related to perceptions of the company at the beginning of a work relationship, perceptions that change over time. Throughout the first months of work, an employee is strongly motivated to fulfil one's responsibilities, is highly committed, and has great expectations regarding the organization, which gives rise to a positive image of the company and the supervisor. The employee sees the workplace through the prism of the supervisor, who is the representative of the company. As far as perceived job satisfaction, organizational support and person-organization fit are concerned, the employee builds an image of the organization on the basis of one's relationship with one's supervisor.

The results obtained confirm that the supervisor support mediate between job seniority and job satisfaction, organizational support, and personorganization fit (tables 3, 4, and 5). As time passes, the employee begins to notice all the faults and drawbacks of one's current employment situation, basing one's opinion on the relationship with the supervisor, and starts to see it as less satisfactory. This leads to a decrease in perceived organizational support and person-organization fit and consequently a reduction in job satisfaction.

\section{Conclusions}

Although the present study had a cross-sectional design, the method applied allowed us to draw conclusions on the directions of correlations between variables. The main shortcoming of the study is that all individuals surveyed were employed by one company, which limits the generalization gradient of the results to a single organization only.

The research presented has practical implications regarding the sources of employee job satisfaction. First and foremost, it demonstrates the important role of the supervisor in satisfaction derived from work by subordinates, who perceive and evaluate both the company's support and the consistency of their own values with the organization's values on the basis of their relationship with their supervisor. In this context, the attitude of the supervisor is the key element in subordinate employees' job satisfaction or lack of it. From a practical perspective, this means that employers should focus on shaping managers' attitudes in appropriate ways, as the behavior of this group of employees towards their subordinates has a decisive influence on employees' job satisfaction and hence their motivation to stay or leave (Liu et al., 2010; Park \& Kim, 2009). The mechanism governing this influence has been described in detail, and possible ways of fulfilling this intention have been indicated. Apart from the direct influence of perceived supervisor support of an employee on job satisfaction, improvement of job satisfaction may occur through an increase in perceived organizational support and increased consistency between the employee's and organization's values. In this context, employers should bear in mind the overriding role of supervisors as leaders and representatives of the company, as the individuals with whom employees have most frequent contact and who create the image of the organization as a supporting vehicle for the employee and are seen to embody the values of the organization. Therefore, employers should carefully select managers who have values consistent with the organization's values and who can appropriately 
communicate them to subordinates. Support of managers by company owners and management boards should also foster the right attitudes among middle and lower-ranking personnel through a sense of appreciation, loyalty, and commitment to fulfilling their responsibilities.

\section{References}

Baron, R. M., \& Kenny, D. A. (1986). The moderatormediator variable distinction in social psychological research: Conceptual, strategic, and statistical considerations. Journal of Personality and Social Psychology, 51(6), 1173-1182.

Bedyńska, S., \& Książek M. (2013). Statystyczny drogowskaz 3. Praktyczny przewodnik wykorzystania modeli regresji oraz równań strukturalnych [Statistical signpost 3. The statistical guide to the use of regression models and structural equation]. Warsaw: Publisher Academic Crux: School of Social Sciences.

Blau, P. M. (1964). Exchange and power in social life. New York, NY: Wiley.

Boxx, W. R., Odom, R. Y., \& Dunn, M. G. (1991). Organizational values and value congruency and their impact on satisfaction, commitment, and cohesion. Public Personnel Management, 20(1), 195-205.

Brown, S. P, \& Peterson, R. A. (1993). Antecedents and consequences of salesperson job satisfaction: Meta- analysis and assessment of causal effect. Journal of Marketing Research, 30, 63-77.

Browne, M. W., \& Cudeck, R. (1993). Alternative ways of assessing model fit. In K. A. Bollen \& J. S. Long (Eds.), Testing structural equation models (pp. 136162). Newsbury Park, CA: Sage.

Byrne, B. M. (1994). Structural equation modeling with EQS and EQS/Windows. Thousand Oaks, CA: Sage Publications.

Cable, D. M., \& DeRue, D. S. (2002). The convergent and discriminant validity of subjective fit perceptions. Journal of Applied Psychology, 87(5), 875884.

Cammann, C., Fichman, M., Jenkins, D., \& Klesh, J. (1979). The Michigan Organizational Assessment Questionnaire (Unpublished manuscript).

Chatman, J. A. (1991). Matching people and organizations: Selection and socialization in public ac- counting firms. Administrative Science Quarterly, 36(3), 459-484.

Chen, C.C., \& Chiu, S.F. (2008). An integrative model linking supervisor support and organizational citizenship behavior. Journal of Business and Psychology, 23(1), 1-10.

Dawley, D., Houghton, J. D., \& Bucklew, N. S. (2010). Perceived organizational support and turnover intention: The mediating effects of personal sacrifice and job fit. The Journal of Social Psychology, 150(3), 238-257.

Dirk, K. T., \& Ferrin, D. L. (2002). Trust in leadership: Meta-analytic findings and implications for research and practice. Journal of Applied Psychology, 87(4), 611-628.

Eisenberger, R., Huntington, R., Hutchison, S., \& Sowa, D. (1986). Perceived organizational support. Journal of Applied Psychology, 71(3), 500-507.

Eisenberger, R., Cummings, J., Armeli, S., \& Lynch, P. (1997). Perceived organizational support, discretionary treatment, and job satisfaction. Journal of Applied Psychology, 82(5), 812-820.

Eisenberger, R., Stinglhamber, F., Vandenberghe, C., Sucharski, I. L., \& Rhoades, L. (2002). Perceived supervisor support: Contributions to perceived organizational support and employee retention. Journal of Applied Psychology, 87(3), 565-573.

Erdogan, B., Kraimer, M. L., \& Liden, R. C. (2004). Work value congruence and intrinsic career success: the compensatory roles of leader-member exchange and perceived organizational support. Personnel Psychology, 57(2), 305-332.

Galletta, M., Portoghese, I., Penna, M. P., Battistelli, A., \& Saiani, L. (2011). Turnover intention among Italian nurses: The moderating roles of supervisor support and organizational support. Nursing and Health Sciences, 13(2), 184-191.

Gutierrez, A. P., Candela, L. L., \& Carver, L. (2012). The structural relationships between organizational commitment, global job satisfaction, developmental experiences, work values, organizational support, and person-organization fit among nursing faculty. Journal of Advanced Nursing, 68(7), 1601-1614.

Harris, R. B. Harris, K. J., \& Harvey, P. (2007). A test of competing models of the relationships among perceptions of organizational politics, perceived 
organizational support, and individual outcomes. The Journal of Social Psychology, 147(6), 631-655.

Hutchison, S. (1997). A path model of perceived organizational support. Journal of Social Behavior and Personality, 12(1), 159-174.

Iplik, F. N., Kilic, K. C., \& Yalcin, A. (2011). The simultaneous effects of person-organization and person-job fit on Turkish hotel managers. International Journal of Contemporary Hospitality Management, 23(5), 644-661.

Kline, R. B. (1998). Principles and practice of structural equation modeling. New York, NY: Guilford Press.

Kottke, J. L., \& Sharafinski, C. E. (1988). Measuring perceived supervisory and organizational support. Educational and Psychological Measurement, 48(4), 1075-1079.

Lauver, K. J., \& Kristof-Brown, A. (2001). Distinguishing between employees' perceptions of person-job and person-organization fit. Journal of Vocational Behavior, 59(3), 454- 470.

Levinson, H. (1965). Reciprocation: The relationship between man and organization. Administrative Science Quarterly, 9(4), 370-390.

Liu, B., Liu, J., \& Hu, J. (2010). Person-organization fit, job satisfaction, and turnover intention: An empirical study in the Chinese public sector. Social Behavior and Personality, 38(5), 615-626.

Maden, C., \& Kabasakal, H. (2014). The simultaneous effects of fit with organizations, jobs and supervisors on major employee outcomes in Turkish banks: does organizational support matter? The International Journal of Human Resource Management, 25(3), 341-366.

Mitchell, T. R., Holtom, B. C., Lee, T. W., Sablynski, C. J., \& Erez, M. (2001). Why people stay: using job embeddedness to predict voluntary turnover. Academy of Management Journal, 44, 1102-1122.

Narayanan, S. S., \& Sekar, P. C. (2009). A Person-organization fit study of college work culture and its impact on behavioural intentions of teachers. Asia Pacific Management Review, 14(2), 121-136.

Netemeyer, R. G., Boles, J. S., McKee, D. O., \& McMurrian, R. (1997). An investigation into the antecedents of organizational behaviors in a personal selling context. Journal of Marketing, 61(3), 85-98.

O’Reilly, C. A., Chatman, J. A., \& Caldwell, D. M. (1991). People and organizational culture: A q-sort approach to assessing person-organization fit. Academy of Management Journal, 34(3), 487-516.

Park, J. S., \& Kim, T. H. (2009). Do types of organizational culture matter in nurse job satisfaction and turnover intention? Leadership in Health Services, 22(1), 20-38.

Piasentin, K. A., \& Chapman, D. S. (2007). Perceived similarity and complementarity as predictors of subjective person-organization fit. Journal of Occupational and Organizational Psychology, 80(2), 341-354.

Podsakoff, P. M., MacKenzie, S. B., \& Bommer, W. H. (1996). Meta-analysis of the relationships between Kerr and Jemier's substitutes for leadership and employee attitudes, role perceptions, and performance. Journal of Applied Psychology, 81(4), 380-399.

Preacher, K. J., Rucker, D. D., \& Hayes, A. F. (2007). Addressing moderated mediation hypotheses: theory, methods, and prescriptions. Multivariate Behavioral Research, 42(1), 185-227.

Preacher, K. J., \& Hayes, A. F. (2008). Asymptotic and resampling strategies for assessing and comparing indirect effects in multiple mediator models. Behavior Research Methods, 40(3), 879-891.

Rhoades, L., Eisenberger, R., \& Armeli, S. (2001). Affective commitment to the organization: the contribution of perceived organizational support. Journal of Applied Psychology, 86(5), 825-836.

Rhoades, L., \& Eisenberger, R. (2002). Perceived organizational support: A review of the literature. Journal of Applied Psychology, 87(4), 698-714.

Schaubroeck, J., \& Fink, L. S. (1998). Facilitating and inhibiting effects of job control and social support on stress outcomes and role behavior: A contingency model. Journal of Organizational Behavior, 19(2), 167-195.

Shore, L. M., \& Tetrick, L. E. (1991). A construct validity study of the survey of perceived organizational support. Journal of Applied Psychology, 76(5), 637-643.

Shore, L. M., \& Shore, T. H. (1995). Perceived organizational support and organizational justice. In R. S. Cropanzano \& K. M. Kacmar (Eds.), Organizational politics, justice, and support: Managing the social climate of the workplace (pp. 149-164). Westport, CT: Quorum. 
Tanova, C., \& Holtom, B. C. (2008). Using job embeddedness factors to explain voluntary turnover in four European countries. The International Journal of Human Resource Management, 19(9), 1553-1568.

Vilela, B. B., González, J. A. V, \& Ferrín, P. F. (2008). Person-organization fit, ocb and performance appraisal: Evidence from matched supervisorsalesperson data set in Spanish context. Industrial Marketing Management, 37(8), 1005-1019.

Werbel, J. D., \& Gilliland, S. W. (1999). The use of person-environment fit in the selection process. In G. Ferris (Ed.), Research in personnel and human resources management, (Vol. 17, pp. 209-245). Greenwich, CT: JAI Press.

Westerman, J. W., \& Cyr, L. A. (2004). An integrative analysis of person-organization fit theories. International Journal of Selection and Assessment, 12(3), 252- 261.

Yoon, J., Han, N. C., \& Seo, Y. J. (1996). Sense of control among hospital employees: An assessment of choice process, empowerment, and buffering hypotheses. Journal of Applied Social Psychology, 26(8), 686-716.

Yoon, J., \& Lim, J. C. (1999). Organizational support in the workplace: The case of Korean hospital employees. Human Relations, 52(7), 923-945. 
